ENCYCLOPEDDIE Encyclopédie berbère

BERBERE

18 | 1997

18 | Escargotière - Figuig

\title{
Fares Nabile
}

\section{J. Déjeux}

\section{OpenEdition}

Journals

Édition électronique

URL : https://journals.openedition.org/encyclopedieberbere/2019

DOI : 10.4000/encyclopedieberbere.2019

ISSN : 2262-7197

\section{Éditeur}

Peeters Publishers

\section{Édition imprimée}

Date de publication : 1 août 1997

Pagination : $2729-2730$

ISBN : 2-85744-948-8

ISSN : 1015-7344

\section{Référence électronique}

J. Déjeux, «Fares Nabile », Encyclopédie berbère [En ligne], 18| 1997, document F06, mis en ligne le 01 juin 2011, consulté le 21 septembre 2021. URL : http://journals.openedition.org/encyclopedieberbere/ 2019 ; DOI : https://doi.org/10.4000/encyclopedieberbere.2019

Ce document a été généré automatiquement le 21 septembre 2021.

(c) Tous droits réservés 


\section{Fares Nabile}

\section{J. Déjeux}

1 Le romancier et poète algérien Nabile Farès est né en 1941 à Collo en Petite Kabylie. Après les grèves dans les lycées en 1956, il partait pour la France puis s'engageait dans l'action militante du F.L.N. (Front de Libération Nationale). Il se réinstallait en France en 1962 et poursuivait des études de philosophie, passant sa maîtrise dans cette discipline en 1967. De novembre 1969 à février 1970, il effectue des travaux de recherches sur la nomadisation des Touaregs de l'est au Mali. Il soutient une thèse en janvier 1972: Littérature orale et anthropologie (à l'Université de Paris X) sur la signification de l'Ogresse dans la littérature orale au Maghreb. Il commence à publier ses romans en 1970 (Yahia pas de chance). En 1981, il travaille à Aix-en-Provence dans le département culturel de la C.I.M.A.D.E. au service des immigrés. Il crée ainsi un groupe de théâtre : "Le Théâtre de la Porte d'Aix" avec des personnes de diverses nationalités.

2 Outre quelques articles sur des problèmes littéraires, son œuvre est constituée essentiellement de cinq romans, d'un récit et de trois recueils de poèmes et d'essais (L'État perdu, Actes Sud, 1982).

3 Le premier recueil Le Chant d'Akli (Paris, Oswald, 1971 réédité en 1981. Paris, L'Harmattan), se rapporte à la Kabylie, le second Chants d'histoire et de vie pour des roses de sable (Paris, L'Harmattan, 1978) est consacré à la guerre menée au Sahara occidental. Le troisième est intitulé L'Exil au féminin. Poèmes d'Orient et d'Occident (Paris, L'Harmattan, 1986).

4 Le dernier roman La Mort de Salah Baye ou la vie obscure d'un Maghrébin (Paris, L'Harmattan, 1981) est, comme ses autres romans, à larges résonances politiques, mais il ne traite pas de la Kabylie : violence des situations, de la parole, de la manière d'être au monde chez un être brimé et contraint, quasiment expulsé de lui-même.

5 Ce sont principalement les autres romans de Nabile Farès qui touchent au problème du pays “inaccompli”, à la Kahéna, à l'Ogresse dans sa caverne, à l'entrée dans le nouveau monde d'aujourd'hui qui est pluriel. Dans un langage souvent difficile, avec une écriture parfois sophistiquée, des acrobaties littéraires et des incantations se répétant de page en page, l'auteur évoque beaucoup de problèmes, de situations, parfois dans des pages denses, d'autres fois en pointillés. Au lecteur de deviner ou d'interpréter. 
C'est pourquoi parmi ses lecteurs beaucoup sont désorientés, avouant que l'auteur est incompréhensible, hermétique même, facilement irrités aussi par la désinvolture des procédés utilisés (ponctuation fantaisiste, abondance des pages blanches, des points de suspension). Il est clair que Nabile Farès ne se livre pas facilement dans des textes qui ne sont pas consommés par des lecteurs pressés. Il faut donc "traverser" le texte, comme dit Farès : «Écrire pour un Maghrébin, c'est toucher l'ancien présent et le futur déjà là ». Tout est là, en effet.

6 Yahia, pas de chance (Paris, Seuil, 1970) est une " autobiographie forcenée ", dit l'auteur. Yahia, 22 ans en févier 1960, a quitté l'Algérie à 17 ans en pleine guerre. Il a dit adieu à l'enfance, franchi le seuil de l'âge adulte, a rencontré claudine avec laquelle il a échangé l'amour. A la fin, il part pour le maquis : il n'avait alors jamais tant eu froid au cœur. Il y a dans ce texte quelque chose d'irréversible : le temps d'hier, mais par-dessus tout une volonté de vivre.

7 Un Passage de l'Occident (Paris, Seuil, 1972) ou "Ali-Saïd le chanceux" se présente là encore comme un texte éclaté. Déjà dans ce roman sont évoqués les problèmes du métissage et du mélange, la recherche des racines perdues, le retour à l'humus profond algérien, l'humus "païen". Les critiques sont précises et l'auteur n'hésite pas à écrire que «La Kabylie souffre d'un malaise insondable, c'est ce qu'on appelle chez nous, le malaise du figuier ». Il est « impensable historiquement », écrit le romancier, de dire à un Kabyle qu'il est Algérien avant d'être Kabyle : «L'Algérie est venue après la Kabylie, c'est un fait. » « En tant qu'Algérien, je suis d'abord Kabyle. »

Le Champ des oliviers (Paris, Seuil, 1972) est le premier volet de la trilogie "La découverte du nouveau monde". L'auteur fait parler l'ogresse de la caverne. Elle n'a pas eu accès à l'écriture et a été subjuguée par l'Étranger venu avec un livre : «Ce livre qui détruisit mon beau royaume d'ogresse naïve. » La prédiction (qui vint avec le livre), dit l'auteur, « installa le terrible règne des marchands. " «L'imposture prophétique se transforma en imposture mercantile, puis, par la suite, en imposture culturelle.» Nabile Farès poursuit ici le dévoilement du traumatisme ancien qui a laissé une plaie mal cicatrisée, ou en tout cas un malentendu.

9 Mémoire de l'Absent (Paris, Seuil, 1974), deuxième volet de ce voyage vers l'amont et de la constatation du pluralisme du monde moderne, est constitué d'allusions, d'énigmes, d'évocations du passé ancien où la Kahéna entre en scène. Le père est l'Absent; avec lui l'identité a disparu. La Vieille, elle, raconte le mythe et l'Histoire, l'épopée qui a tourné court et qui a laissé le pays "inaccompli". "Le pays est devenu plusieurs". Exil, naufrage, émigration, possession de la Ville, il faut désormais assumer une condition nouvelle, une manière d'être renouvelée pour vivre dans le Nouveau Monde.

10 L'exil et le désarroi (Paris, Maspéro, 1976) est le troisième volet de la trilogie. L'auteur dévoile son amertume. Le héros est revenu au pays pour constater les scléroses, les silences, dans Alger "où les hommes ont décidé de se taire ou: d'adresser des louanges ». Désarroi donc. Pour lui le nouveau monde doit être au-delà du Livre, de la Théologie : «Le livre ne me suffit plus, il me faut atteindre le monde, par delà le Livre (...). J'ai écouté les paroles du Livre et j'ai senti, en moi, une sorte d'esclavage (...). Je désire comprendre le monde, sans le Livre.»

11 Ainsi donc dans toute cette œuvre poétique et romanesque, symbolique et parfois hermétique, l'auteur n'entend pas échapper à une visée d'ordre politique. L'identité ancienne a été violentée par l'arrivée des Arabes au Maghreb, puis des Français au XIX siècle. Il faut constater la bâtardise, d'une part et, d'autre part, l'exil au cœur même de 
l'Algérie indépendante. D'où la rupture, la sortie du cercle pour vivre "ailleurs". Pour mieux faire sentir au lecteur son amertume devant ce monde, Nabile Farès introduit lui-même les violences dans ses textes : mélange des genres, typographies fantaisistes, jeux de mots et calembours pour déconcerter, style heurté, phrases coupées par des points après chaque mot parfois. "Chance" et "pas de chance", "Passager", "Mémoire", "Absent", "Exil", "Désarroi", "Mort de Salah Baye", tout parait centré autour d'une idée: celle de l'inaccompli, du souvenir nostalgique, d'un exil étranger qu'il a fallu assumer pour échapper à la mort, pour vivre. Le "Chanceux" est tombé en gloire à la guerre. Lui, au moins, ne souffre plus. Le "pas de la chance", Yahia doit continuer, lui, à le faire ailleurs.

INDEX

Mots-clés : Biographie 